\author{
International Journal of Innovative Research in \\ Electrical, Electronics, Instrumentation and Control Engineering
}

Vol. 9, Issue 10, October 2021

DOI: 10.17148/IJIREEICE.2021.91013

\title{
Aerodynamic force measurements on non-plane 'c' wing
}

\author{
Preethi $^{1}$, Sivaraman $^{2}$, Magesh $_{\text {kumar }}{ }^{3}$, Mahalakshmi $^{4}$, Visalatchi $^{5}$ \\ 1,4,5 UG - Aeronautical Engineering, Hindusthan college of engineering and technology, Coimbatore, Tamil Nadu \\ ${ }^{2,3}$ Assistant Professor, Aeronautical Engineering, Hindusthan college of engineering and technology, \\ Coimbatore, Tamil Nadu
}

\begin{abstract}
An aerodynamic force is a force exerted on a body by the air (or other gas) in which the body is immersed, and is due to the relative motion between the body and the gas. There are two causes of aerodynamic force. The normal force due to the pressure on the surface of the body.

The shear force due to the viscosity of the gas, also known as skin friction. When an aerofoil (such as a wing) moves relative to the air, it generates an aerodynamic force in a rearward direction, at an angle determined by the direction of relative motion. This aerodynamic force is commonly resolved into two components, acting through the body's centre of pressure. Drag is the force component parallel to the direction of relative motion, Lift is the force component perpendicular to the

direction of relative motion. In this experimentation, the aerodynamic forces were found over three wing models such as Straight wing, $\mathrm{C}$ wing, and Inverted $\mathrm{C}$ wing. The aircraft wing model was designed by referring to the dimension of an aircraft Airbus A300 -600 R wing with airfoil NACA

64215(((Kaushik et al. 2018). There were three models such as straight wing, $C$ wing, and inverted $C$ wing having the same lifting area had been fabricated. The design procedure of the wing model and Blower Balance test have been presented here.
\end{abstract}

Keywords: Aerodynamics, straight wing, c wing, inverted c wing, Blower balance tunnel

\section{INTRODUCTION}

An aerodynamic force is a force exerted on a body by the air(or other gas) in which the body is immersed, and is due to the relative motion between the body and the gas. There are two causes of aerodynamics force. Drag is the force component parallel to the direction of relative motion. Lift is the force component perpendicular to the direction of relative motion. Aerodynamics is the way air moves around things.

The rules of aerodynamics explain how an airplane is able to fly. Anything that moves through air reacts to aerodynamics. A rocket blasting off the launch pad and a kite in the sky react to aerodynamics. Aerodynamics even acts on cars, since air flows around cars.

Drag is the aerodynamic force that opposes an aircraft's motion through the air. If there is no fluid, there is no drag. Drag is generated by the difference in velocity between the solid object and the fluid. There must be motion between the object and the fluid. If there is no motion, there is no drag.

In fluid dynamics, drag is a force acting opposite to the relative motion of any object moving with respect to a surrounding fluid. This can exist between two fluid layers or a fluid and a solid surface. In fluid dynamics, drag (sometimes called air resistance, a type of friction, or fluid resistance, another type of friction or fluid friction) is a force acting opposite to the relative motion of any object moving with respect to a surrounding fluid.

This can exist between two fluid layers (or surfaces) or a fluid and a solid surface. Unlike other resistive forces, such as dry friction, which are nearly independent of velocity, drag force depends on velocity. Drag force is proportional to the velocity for a laminar flow and the squared velocity for a turbulent flow. Even though the ultimate cause of a drag is viscous friction, the turbulent drag is independent of viscosity. 


\section{International Journal of Innovative Research in \\ Electrical, Electronics, Instrumentation and Control Engineering}

Vol. 9, Issue 10, October 2021

\section{DOI: 10.17148/IJIREEICE.2021.91013}

\section{EXPERIMENTAL METHODS OR METHODOLOGY}

The wing geometry of commercial aircraft Airbus A300-600R was selected for the design. It is a wide-body twin-engine jet airliner that was developed and manufactured by Airbus. The model fabricated was a scaled-down of the original prototype.Since the wind tunnel test section available for the study was limited. The geometry of the wing had been taken as follows,

Scaling ratio $1: 50$

The span of the wing is $448 \mathrm{~mm}$

Root chord length is $180 \mathrm{~m}$

Tip chord length is $54 \mathrm{~mm}$

The height of the vertical winglet is $103 \mathrm{~mm}$ (23\% of the wingspan (Demasi et. all 2014). The height of the horizontal wing let is $116 \mathrm{~mm}$ ( $26 \%$ of the wingspan (Demasi et. all 2014) The sweep angle of the wing is $19^{\circ}$

Cant angle $90^{\circ}$

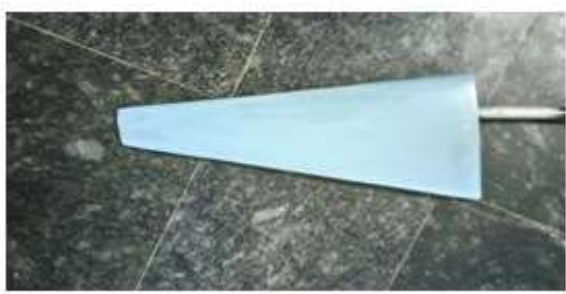

(a)

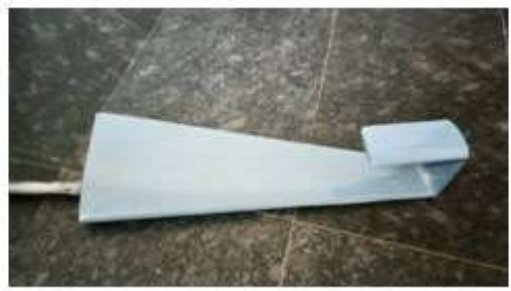

(b)

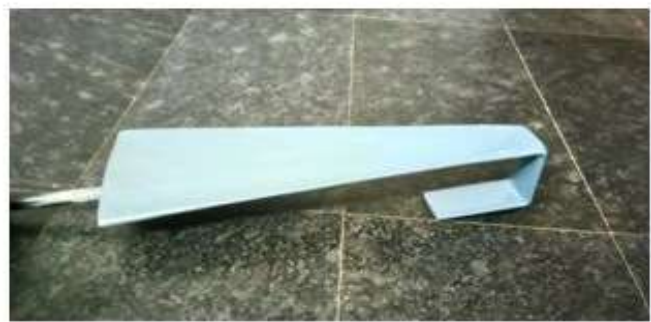

(c)

Figure 2.1. Fabricated models of a straight wing, C-wing, and inverted C-wing

The $\mathrm{X}$ coordinates and Y coordinates were taken from the literature used to generate airfoil in the CATIA V5 R20 workbench then extrude the airfoil into the wing. Then, the vertical and horizontal extrusions at the wingtip were drawn with an airfoil of required geometry to generate the $\mathrm{C}$ surface. The inverted $\mathrm{C}$ winglet had been drawn by extruding the vertical surface to the negative coordinate. Based on CATIA V5 R20, the three models such as the commercial wing, the wing with $\mathrm{C}$-winglet, and the wing with inverted $\mathrm{C}$-winglet were fabricated by compression molding (Janardhanan et al. 2019).

The fabricated wing models of (a) straight wing, (b) $\mathrm{C}$ wing, and (c) Inverted $\mathrm{C}$ wing respectively are shown in figure 2.2. All the wings have the same planar area and fabricated in the compression molding process (Tanaka and Wood 2010).

\subsection{Blower balance tunnel :}

The test was carried out at Hindusthan College of Engineering and Technology, Coimbatore. The low-speed subsonic wind tunnel balance is shown in figure.

The specifications are, Blower type:

a) Axial with a circular duct for (delivery and suction)

b) Operated at $50 \mathrm{~Hz}$

Motor: AC motor with thyristor speed controller (AC drive) Drive: AC type

Electrical input: Single phase, $220 \mathrm{~V}$, AC supply with neutral and earth. Test section speed : 5-10 m/s. 


\section{International Journal of Innovative Research in Electrical, Electronics, Instrumentation and Control Engineering}

Vol. 9, Issue 10, October 2021

\section{DOI: 10.17148/IJIREEICE.2021.91013}

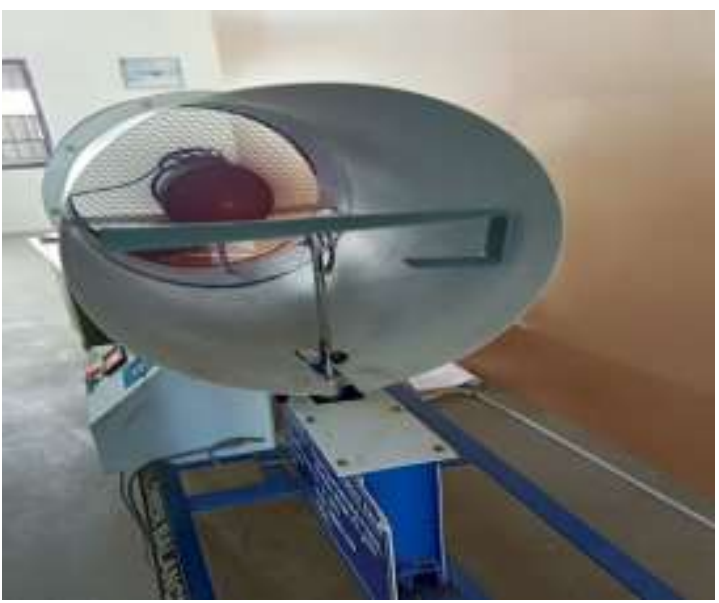

Figure.2.2. Blower balance tunnel

The aerodynamic force measurements had been investigated on three fabricated models such as commercial wing, Cwing, and inverted C-wing. Lift and Drag force were determined in three- component balance in blower tunnel balance. Due to the test section flow speed limitation, the test section speed was set as $5 \mathrm{~m} / \mathrm{s}$. However, this could be useful in predicting the aerodynamic characteristics of wings in very speed flight i.e less than stall speed(()( Richardson and Power 1996). Stall speed is the slowest speed that an airplane can fly. The typical value for commercial airplanes is ranging from $8-15 \mathrm{~m} / \mathrm{s}$.

\section{RESULTS AND DISCUSSION}

The aerodynamic forces namely lift and drag had been determined at various angles of attack such as $0^{\circ}, 5^{\circ}$ and $10^{\circ}$ using wind tunnel balance. The results are tabulated in table 3.1 and 3.2

Table.3.1. Lift and Drag for different wing models

\begin{tabular}{|l|l|l|l|l|l|l|l|}
\hline \multirow{2}{*}{ S1. No } & & \multicolumn{3}{|c|}{ Drag (N) } & \multicolumn{2}{c|}{ Inverted } \\
\cline { 2 - 8 } & & Conventional wing & & Inverted & Conventional wing & & \\
\hline & & & 0.1962 & 0.4905 & 0.00981 & 0.00981 & 0.00981 \\
\hline & & 0.1962 & 0.1962 & 1.4715 & 0.01962 & 0.00981 & 0.02943 \\
\hline
\end{tabular}

It is inferred from table 3.1 that the Lift and Drag increase with an increase in the angle of attack. The Coefficient of Lift is higher for the inverted $\mathrm{C}$ wing over other wings. Likewise, the coefficient of drag is lesser for the inverted $\mathrm{C}$ wing. But during the investigation, it was seen that the inverted $\mathrm{C}$ wing underwent a heavy vibration. The magnitude of vibration in the tunnel itself was very high, which may lead to structural failure of the wing due to flutter in cruise flight at maximum flight speed. Hence it could not be recommended to incorporate into the straight wing.

Table.3.2 Lift to Drag ratio for different wing models

\begin{tabular}{|c|c|c|c|c|}
\hline \multirow{2}{*}{ Sl. No } & \multirow{2}{*}{ Alpha } & \multicolumn{3}{|l|}{ L/D } \\
\hline & & Conventional wing & C wing & Inverted $\mathrm{C}$ wing \\
\hline 1 & $0^{\circ}$ & 0 & 20 & 50 \\
\hline 2 & $5^{\circ}$ & 10 & 20 & 50 \\
\hline 3 & $10^{\circ}$ & 16.67 & 30 & 23.99 \\
\hline
\end{tabular}




\section{International Journal of Innovative Research in Electrical, Electronics, Instrumentation and Control Engineering}

Vol. 9, Issue 10, October 2021

\section{DOI: $10.17148 /$ IJIREEICE.2021.91013}

From table 3.2, it is evident that the Lift / Drag ratio is higher in the inverted C wing than in other wing models $((()((\mathrm{Raj}$ Arora et al. 2005). The inverted $C$ wing was undergoing very high vibration and hence it could not be incorporated in the commercial wing due to the structural limitation. Hence, the $\mathrm{C}$ wing configuration could be preferred to the conventional straight wing so as to get enhanced aerodynamic efficiency.

\section{CONCLUSION}

Hence, with all the results obtained from the various studies undertaken, it could be observed that the $\mathrm{C}$ wing provides better aerodynamic characteristics without compensating much structural integrity and design complexity.

From the results and discussions, it was understood that the optimum angle of attack is $5^{\circ}$. At that angle, the $\mathrm{C}$-wing has an optimum lift and minimum drag and also has the optimum lift to drag ratio. The inverted C-wing creates more lift when compared to the $\mathrm{C}$-wing. But inverted $\mathrm{C}$-wing produces more vibration at an angle of attack of $5^{\circ}$ which causes the structural damage $((($ Jansen et al. 2010). Finally, it can be concluded from the experimental investigation of the commercial wing, the $\mathrm{C}$-wing, and inverted $\mathrm{C}$-wing, the $\mathrm{C}$-winglet has the optimum performance at a $5^{\circ}$ angle of attack.

\section{REFERENCES}

1. https://doi.org/10.2514/1.C031456.

2. https://doi.org/10.2514/1.C031060 